\title{
The CIHR Circulatory and Respiratory Health Institute
}

\section{Malcolm King PhD, Past-President, CTS, Member of the CIHR Governing Council}

$\mathrm{T}$ The Canadian Institutes of Health Research (CIHR) was officially established on June 7, 2000. Among the 13 institutes that were created, the Institute for Circulatory and Respiratory Health (C\&R or CnR), which brings together researchers in the fields of heart, stroke, lung and blood research, has become the principal outlet for respiratory research in this country. Although this large, combined institute was not the first choice of our society or of the respiratory research community at large, we must respect this choice within the context of the new direction for Canadian health research and help to make it work. Over this past summer, the process of recruiting the scientific directors and advisory board members for each CIHR institute has proceeded at a rapid pace. As we go to press, the decisions on the appointment of the 13 inaugural scientific directors are being made. In addition, over the next few weeks, the institute advisory boards will be appointed. The CIHR Governing Council has the ultimate responsibility for these appointments. The Council represents a very broad cross-section of the health research community in Canada; all of us on the Council sincerely wish to see the very best team of directors and board members selected to fulfill these roles.

On September 16 to 17 in Toronto, Ontario, I had the pleasure of co-hosting a conference with my counterparts in the Canadian Cardiovascular Society and the Stroke Society, thanks to a CIHR Opportunity grant, "Strategic planning for respiratory health research". This conference served as the first major opportunity to bring together the participating groups of the C\&R. The conference was highlighted by a presentation from Dr Carl Roth of the National Heart, Lung, and Blood Institute (USA) summarizing the American experience with a multidisciplinary institute. A number of issues were addressed by the working groups around determining research priorities, resource distribution, integration, capacity building and communications. From these discussions there arose a collection of the 'best advice' for the sponsoring organizations and the CIHR, and an offer to work with the incoming scientific director and advisory board to turn this advice into policy and action. The complete report can be accessed on the Canadian Lung Association's web site at www.lung.ca.

I encourage the respiratory research community to continue to participate in this process. We need to keep the CIHR informed about the important issues in our field of respiratory research. The primary in-

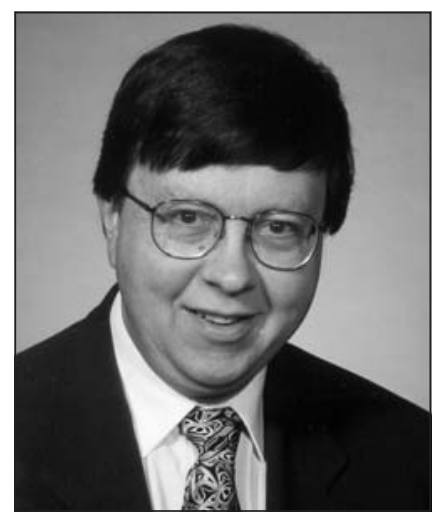
stitute of interest for our respiratory community and for our voluntary sector is, of course, the C\&R. We (the Canadian Thoracic Society/Canadian Lung Association) need to make our presence known in this larger institute. However, let us not forget that the entire CIHR is open to respiratory health research. There is now not just one outlet for our research but in fact several because most of the other institutes have a specific interest in respiratory health. For example, the mandates of the Institutes of Infection and Immunity, and the Institute of Cancer Research clearly include a major respiratory component, and the cross-cutting theme institutes - Genetics; Healthy Aging; Population and Public Health; Human Development and Child and Youth Health; Health Services and Policy Research; Gender and Health; and Aboriginal People's Health - all include various aspects of respiratory health research in their extended mandates. Even in those institutes for which the connection is more distant (Neurosciences, Mental Health and Addiction; Musculoskeletal Health and Arthritis; and Nutrition, Metabolism and Diabetes), collaborations at basic and multidisciplinary levels involving respiratory scientists will be expected and encouraged. Excellence in research, supported by the peer review process established by the Medical Research Council, is still the main criterion for support. Respiratory research in Canada has a long tradition of excellence; let's maintain it and build on it. 


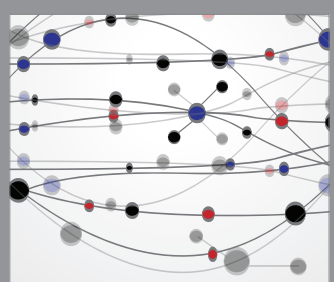

The Scientific World Journal
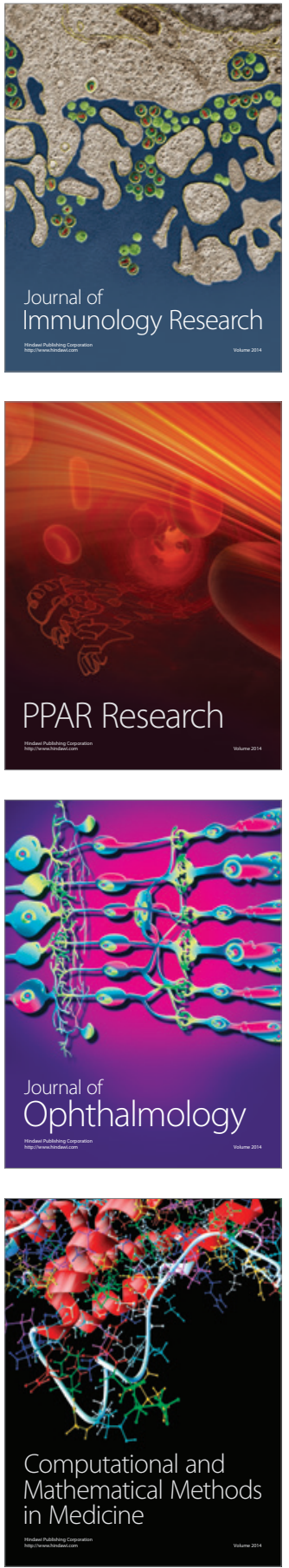

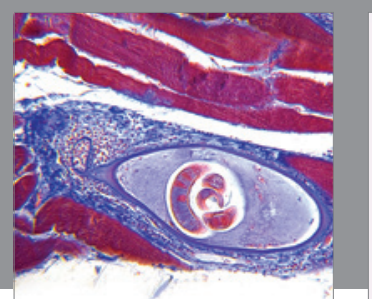

Gastroenterology Research and Practice

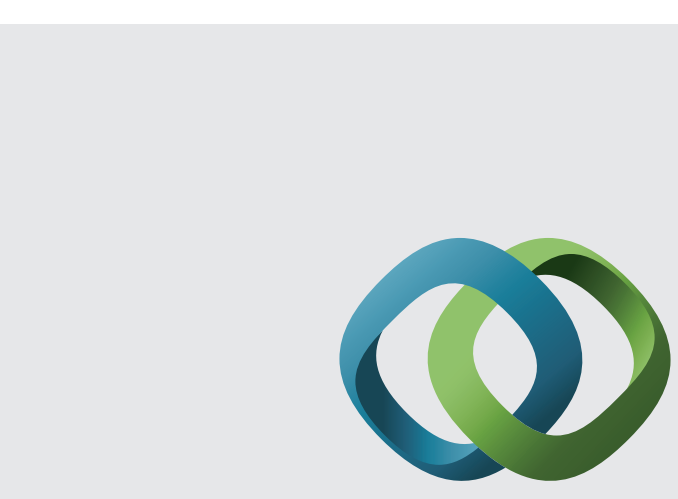

\section{Hindawi}

Submit your manuscripts at

http://www.hindawi.com
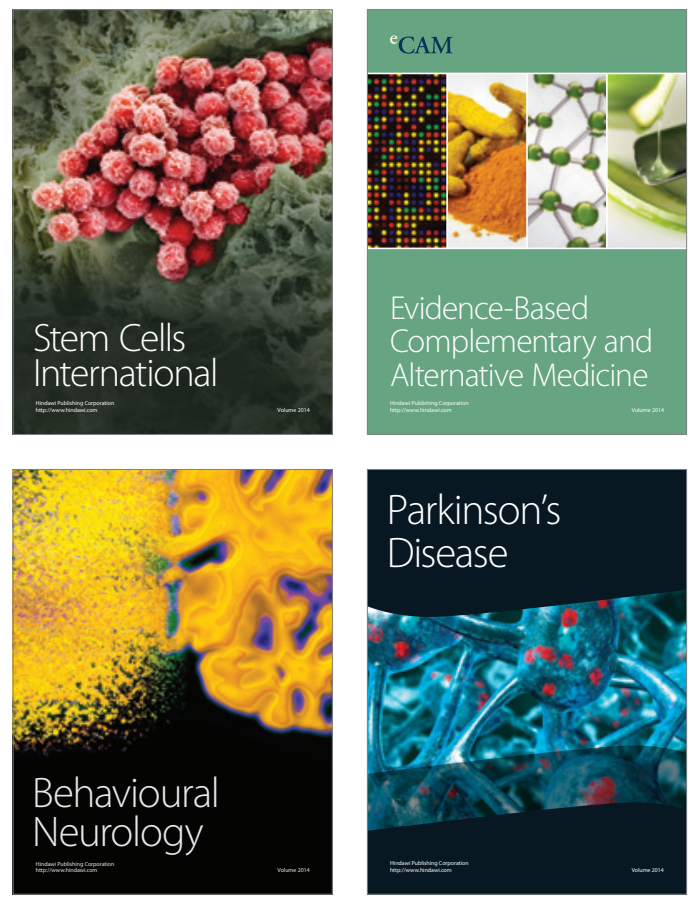
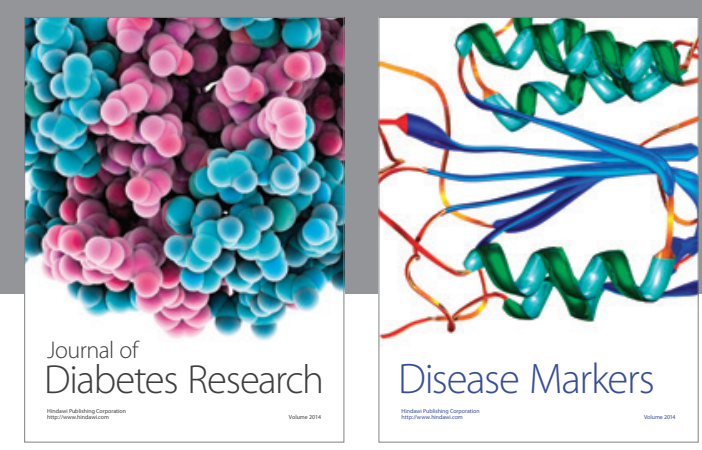

Disease Markers
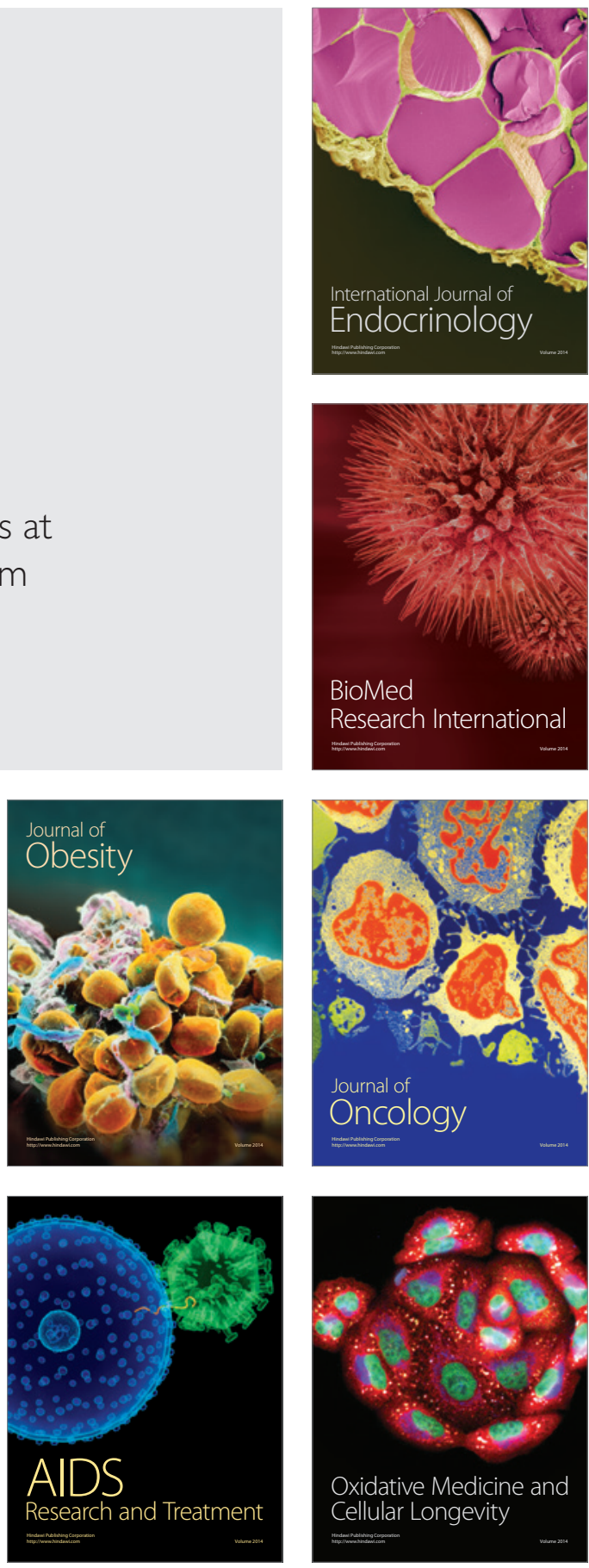